$06.1 ; 07.2 ; 08 ; 13.1$

\title{
Подложки с алмазным теплоотводом для эпитаксиального роста GaN
}

\author{
() И.О. Майборода ${ }^{1}$, И.А. Черных ${ }^{1}$, В.С. Седов ${ }^{2}$, А.С. Алтахов ${ }^{2}$, А.А. Андреев ${ }^{1}$, \\ Ю.В. Грищенко ${ }^{1}$, Е.М. Колобкова ${ }^{1}$, А.К. Мартьянов ${ }^{2}$, В.И. Конов ${ }^{2}$, М.Л. Занавескин ${ }^{1}$ \\ ${ }^{1}$ Национальный исследовательский центр „Курчатовский институт“, Москва, Россия \\ ${ }^{2}$ Институт общей фризики им. А.М. Прохорова РАН, Москва, Россия \\ E-mail: mrlbr@mail.ru
}

Поступило в Редакцию 25 ноября 2020г.

В окончательной редакции 16 декабря 2020 г.

Принято к публикации 17 декабря 2020г.

\begin{abstract}
Изготовлены пластины кремния с теплоотводом из поликристаллического алмаза, в которых слои кремния и алмаза имели толщину $234 \mathrm{~nm}$ и $250 \mu \mathrm{m}$ соответственно. Теплопроводность алмаза составила $1290 \pm 190 \mathrm{~W} /(\mathrm{m} \cdot \mathrm{K})$. Методом аммиачной молекулярно-лучевой эпитаксии на подложках кремния с теплоотводом из поликристаллического алмаза выращены нитридные гетероструктуры с двумерным электронным газом. Подвижность электронов в двумерном электронном газе и его слоевое сопротивление составили $1600 \mathrm{~cm}^{2} /(\mathrm{V} \cdot \mathrm{s})$ и $300 \Omega / \square$ соответственно.
\end{abstract}

Ключевые слова: транзистор с высокой подвижностью электронов, нитридная гетероструктура, нитрид галлия, кремний, алмаз.

DOI: 10.21883/PJTF.2021.07.50792.18630

Благодаря своим физическим свойствам нитрид галлия $(\mathrm{GaN})$ и транзисторы с высокой подвижностью электронов на основе $\mathrm{GaN}$ высоко востребованы в силовой и сверхвысокочастотной (СВЧ) электронике [1]. Высокие удельные мощности определяют необходимость эффективного отвода тепла из рабочей области транзисторов. Таким образом, теплопроводность материалов подложки становится фактором, определяющим предельные характеристики СВЧ дискретных транзисторов и монолитных интегральных схем. Поскольку алмаз имеет самую высокую теплопроводность среди диэлектриков, идея использования его для отвода тепла вместо карбида кремния или кремния в нитридных устройствах чрезвычайно привлекательна. Попытки прямого способа осаждения нитридных гетероструктур на алмаз успеха не принесли, поэтому поиск новых альтернативных путей интеграции алмаза в нитридную полупроводниковую технологию актуален до сих пор. Сообщается об экспериментах по сращиванию поверхностей $\mathrm{GaN}$ и алмаза посредством бондинга при комнатной температуре [2]. В работе [3] рассматривается возможность отведения тепла с помощью алмазных пленок, сформированных на поверхности контактов транзисторов. При эпитаксиальном росте $\mathrm{GaN}$ на алмазных подложках появляется проблема, связанная со значительной разницей между коэффициентами теплового расширения (КТР) GaN и алмаза. После проведения эпитаксии во время охлаждения нитридная пленка на алмазной подложке может треснуть из-за разницы в сжатии нитридной пленки и алмаза, если не предпринять меры по снижению чрезмерной деформации растяжения в нитридной пленке [4].

В настоящей работе представлен способ создания подложек, представляющих собой тонкий слой кремния на поликристаллическом алмазе высокой теплопроводно- сти, и показано, что подобные подложки обеспечивают качество эпитаксиальных гетероструктур не хуже, чем при росте на стандартных подложках кремния.

Для изготовления кремниевых подложек с алмазным теплоотводом были использованы подложки кремния ориентации (111) на изоляторе толщиной $0.675 \mathrm{~mm}$, в которых толщины кремния и оксида кремния составляли 234 и $433 \mathrm{~nm}$ соответственно. Изготовление подложки схематично показано на рис. $1, a$.

Поликристаллический алмаз был нанесен методом химического газофазного осаждения в СВЧ-реакторе плазмохимической установки для выращивания алмазов WT-100 (2.45 GHz) производства ООО „Вандер Технолоджис“" [5] в газовой смеси метан-водород $\left(\mathrm{CH}_{4} / \mathrm{H}_{2}\right)$ при следующих условиях: общий расход газа $500 \mathrm{sccm}$, давление газа 75 Torr и СВЧ-мощность $4.5 \mathrm{~kW}$. Первые два часа роста концентрация $\mathrm{CH}_{4} / \mathrm{H}_{2}$ поддерживалась на уровне $6 \%$ для обеспечения хорошей адгезии и высокого качества пленки, а затем повышалась до 10\%, чтобы увеличить скорость осаждения. Температура подложки поддерживалась на уровне $840 \pm 20^{\circ} \mathrm{C}$, измерения осуществлялись с помощью двухлучевого пирометра Williamson 81-35-С. Длительность процесса осаждения составила $72 \mathrm{~h}$. Толщина пленки и скорость роста контролировались in situ методом лазерной интерферометрии [6]. Толщина выращенного слоя алмаза составляла $250 \mu \mathrm{m}$. Теплопроводность измерялась лазерным флэш-методом [7] и составила $1290 \pm 190 \mathrm{~W} /(\mathrm{m} \cdot \mathrm{K})$, что практически в 3 раза превышает теплопроводность карбида кремния.

Слой кремния утоняли до нужной толщины путем последовательного механического шлифования и плазменного травления в дифториде ксенона $\left(\mathrm{XeF}_{2}\right)$. 


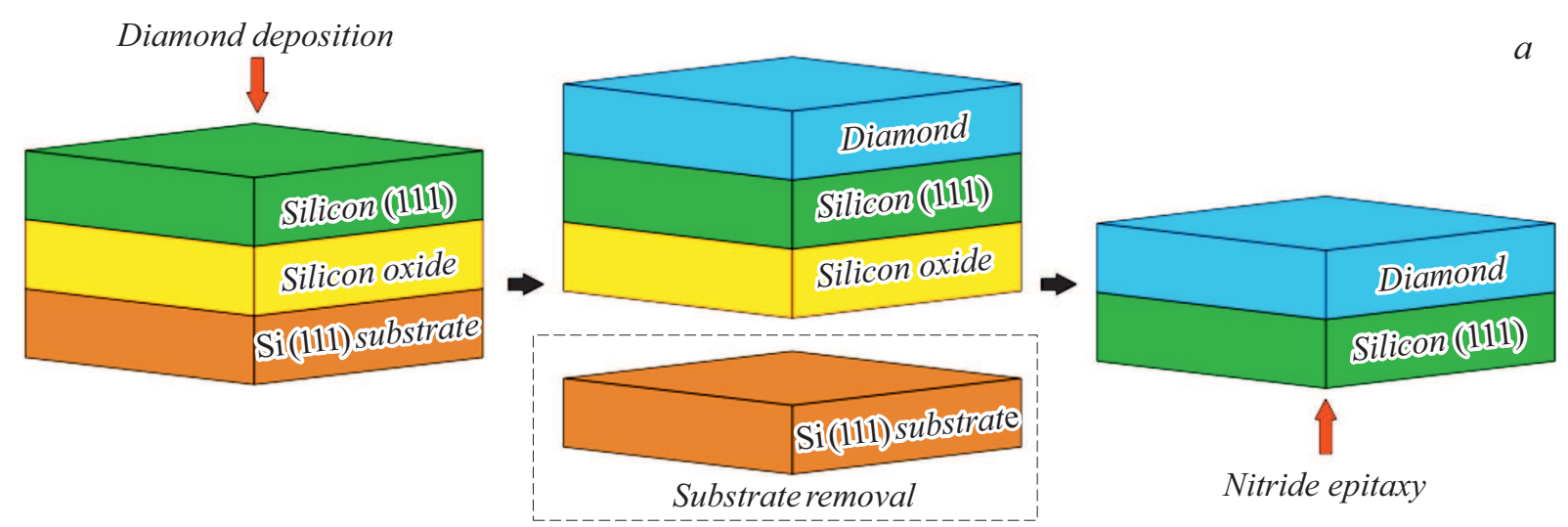

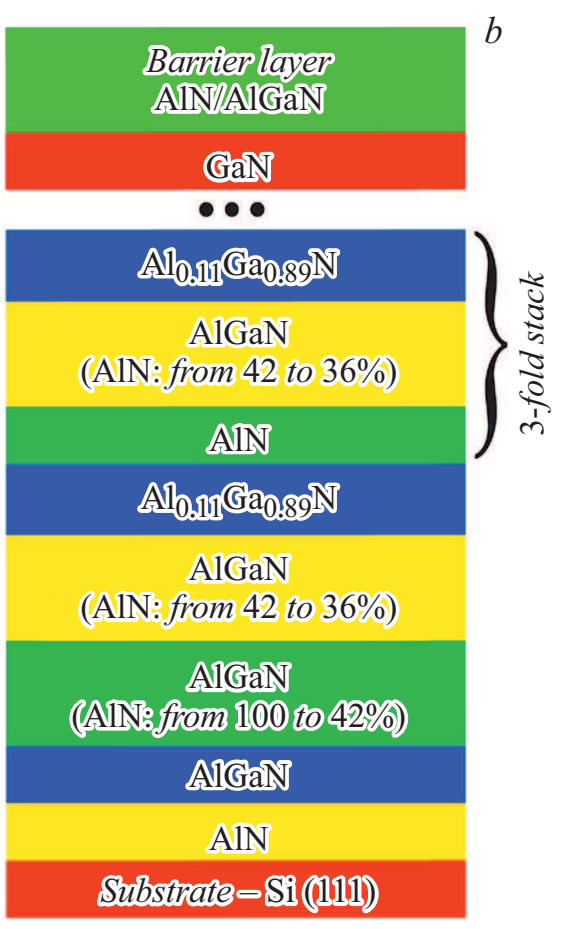

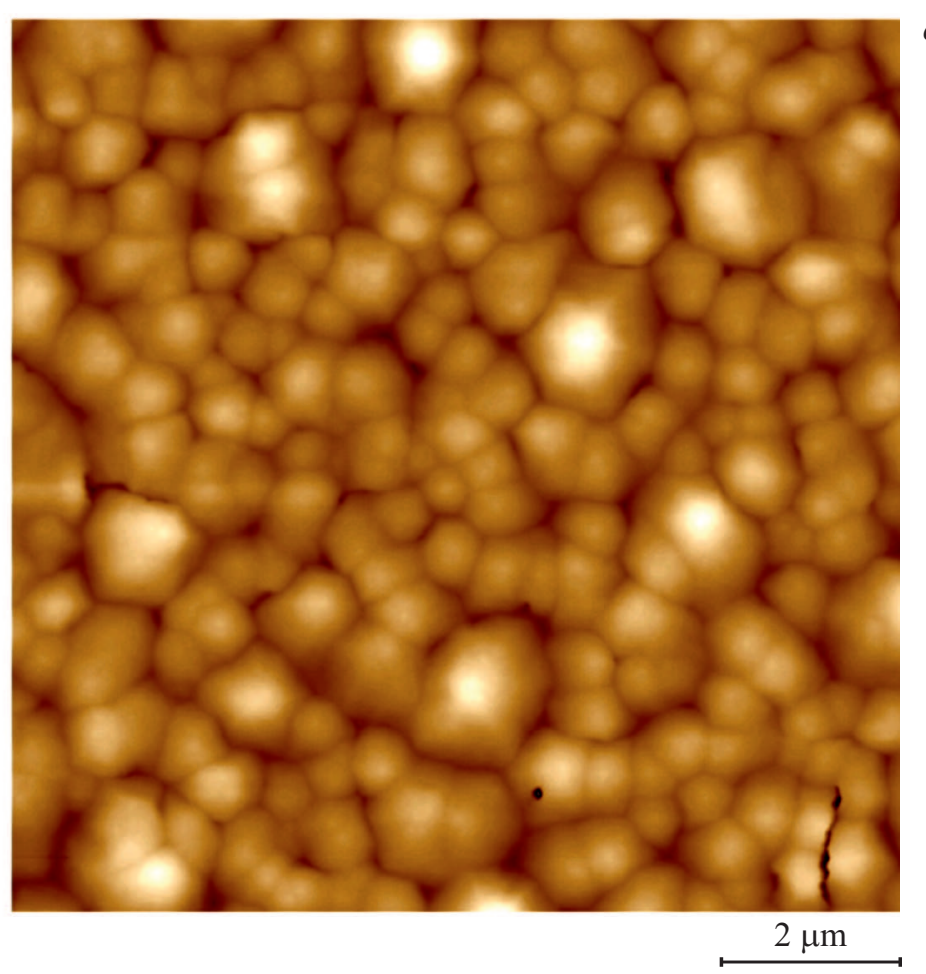

Рис. 1. $a-$ изготовление алмазного теплоотвода на подложке кремния; $b-$ слои гетероструктуры; $c-$ АСМ-изображение поверхности нитридной гетероструктуры на подложке кремния $(10 \times 10 \mu \mathrm{m})$.

Гетероструктуры GaN были выращены в установке молекулярно-лучевой эпитаксии (МЛЭ) SemiTeq STE3N с аммиачным $\left(\mathrm{NH}_{3}\right)$ источником азота. Сначала была выращена гетероструктура на пластине $\mathrm{Si}$ (111), затем процесс роста был повторен на подложке кремния с алмазным теплоотводом. Схема структуры показана на рис. $1, b$. С помощью нитридизации в потоке аммиака на поверхности кремния формировался кристаллический нитрид кремния $\left(\mathrm{Si}_{3} \mathrm{~N}_{4}\right)$. Затем при $600^{\circ} \mathrm{C}$ были нанесены два монослоя алюминия. Далее при $900^{\circ} \mathrm{C}$ был нанесен низкотемпературный слой нитрида алюминия (AIN) толщиной $10 \mathrm{~nm}$. При $1200^{\circ} \mathrm{C}$ формировался буферный слой $\mathrm{AlN}$ с добавленным потоком галлия, чтобы уменьшить плотность дефектов и сгладить рельеф [8]. Затем были выращены два последовательных слоя AlGaN c постепенно меняющимся содержанием Al. В первом градиентном слое мольная доля $\mathrm{GaN}$ увеличивалась за счет охлаждения подложки. Во время осаждения второго слоя содержание $\mathrm{Al}$ постепенно уменьшалось за счет охлаждения источника алюминия. После ростового процесса во время охлаждения слои кремния, алмаза и нитрида сжимались с разными скоростями из-за разницы в КТР. Для компенсации этой разницы накапливалось сжимающее напряжение с помощью трех слоев $\mathrm{AlGaN}-\mathrm{AlN}-\mathrm{AlGaN}$, выращенных один за другим. Рост завершался слоем $\mathrm{GaN}$ толщиной $300 \mathrm{~nm}$ и барьерным слоем AlN/AlGaN общей толщиной $26 \mathrm{~nm}$. Суммарная толщина нитридных слоев составила $1.8 \mu \mathrm{m}$.

Образец на кремниевой подложке не имел трещин. Область деформации пластины не превышала $3 \mu \mathrm{m}$. 


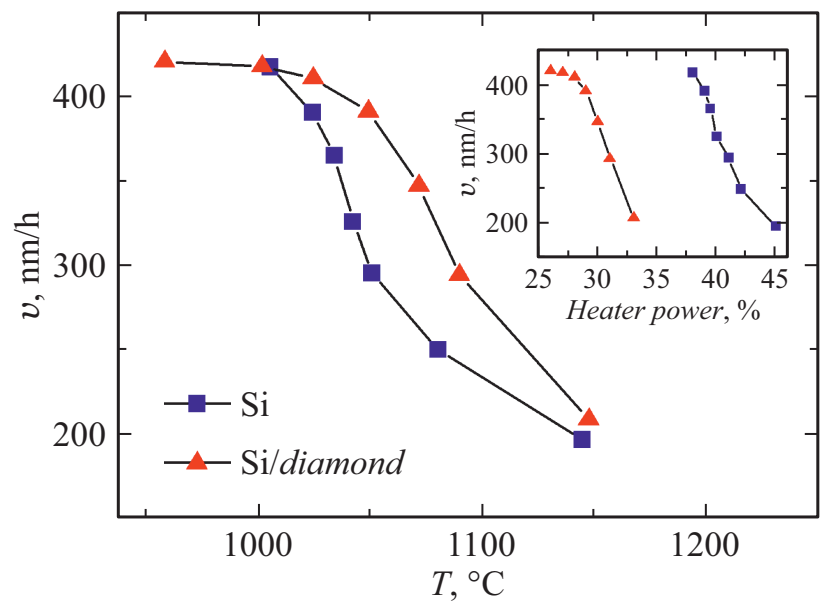

Рис. 2. Зависимость скорости роста $\mathrm{AlGaN}$ от показаний пирометра. На вставке изображена зависимость скорости роста от мощности нагревателя.

Поверхность образца, выращенного на кремнии, была изучена методом атомно-силовой микроскопии (АСМ) в полуконтактном режиме на сканирующем зондовом микроскопе NTEGRA Aura (NT-MDT). Полученная поверхность (рис. 1,c) состояла из ступенчатых пирамид, характерных для аммиачной МЛЭ. Среднеквадратичная шероховатость поверхности составляла $2.3 \mathrm{~nm}$. Структуры содержали двумерный электронный газ с подвижностью носителей $1400 \mathrm{~cm}^{2} /(\mathrm{V} \cdot \mathrm{s})$ и слоевым сопротивлением $300 \Omega / \square$. Электрофизические измерения описаны в работе [9]. Плотность тока насыщения достигала $0.95 \mathrm{~A} / \mathrm{mm}$ (расстояние между контактами $4 \mu \mathrm{m}$ ).

Поскольку при применении МЛЭ образцы нагреваются излучением без прямого контакта, температура подложек из разных материалов при одинаковой мощности нагревателя может различаться на сотни градусов. Для определения температурного соответствия подложек кремния и кремния с алмазным теплоотводом была проведена калибровка путем выращивания $\mathrm{AlGaN}$ в условиях десорбции галлия на подложках кремния и кремния с алмазным теплоотводом. В условиях избыточного давления аммиака скорость роста $\mathrm{AlGaN}$ в интервале температур от 800 до $1200^{\circ} \mathrm{C}$ зависит только от температуры подложки [8]. На рис. 2 представлены зависимости скорости роста от температуры подложек, измеренные инфракрасным пирометром. На вставке к рис. 2 показаны зависимости скорости роста $\mathrm{AlGaN}$ от мощности нагревателя для обоих типов подложек. Видно, что мощность, необходимая для поддержания одинаковой температуры на разных подложках, различается на 10\% мощности нагревателя. Показано, что разница в фактических температурах подложек кремния и кремния с алмазным теплоотводом достигает $50^{\circ} \mathrm{C}$ при тех же показаниях оптического пирометра.

Согласно результатам описанной калибровки, рост гетероструктуры на подложке кремния с теплоотводом из поликристаллического алмаза проводился при мощностях нагревателя, смещенных вниз на 8\% относительно значений, используемых на кремниевых подложках. Гетероструктура была выращена на площади $14 \times 14 \mathrm{~mm}$, трещин на полученной гетероструктуре обнаружено не было. Следовательно, сжимающие напряжения, накопленные при осаждении эпитаксиальных слоев, оказались достаточными для компенсации растягивающих напряжений, возникающих из-за разницы КТР алмаза, кремния и нитридов при охлаждении. Метод АСМ показал (рис. 3,a), что пленка имеет рельеф, аналогичный рельефу пленок на пластине монокристаллического кремния (рис. 1,c). Среднеквадратичная шероховатость
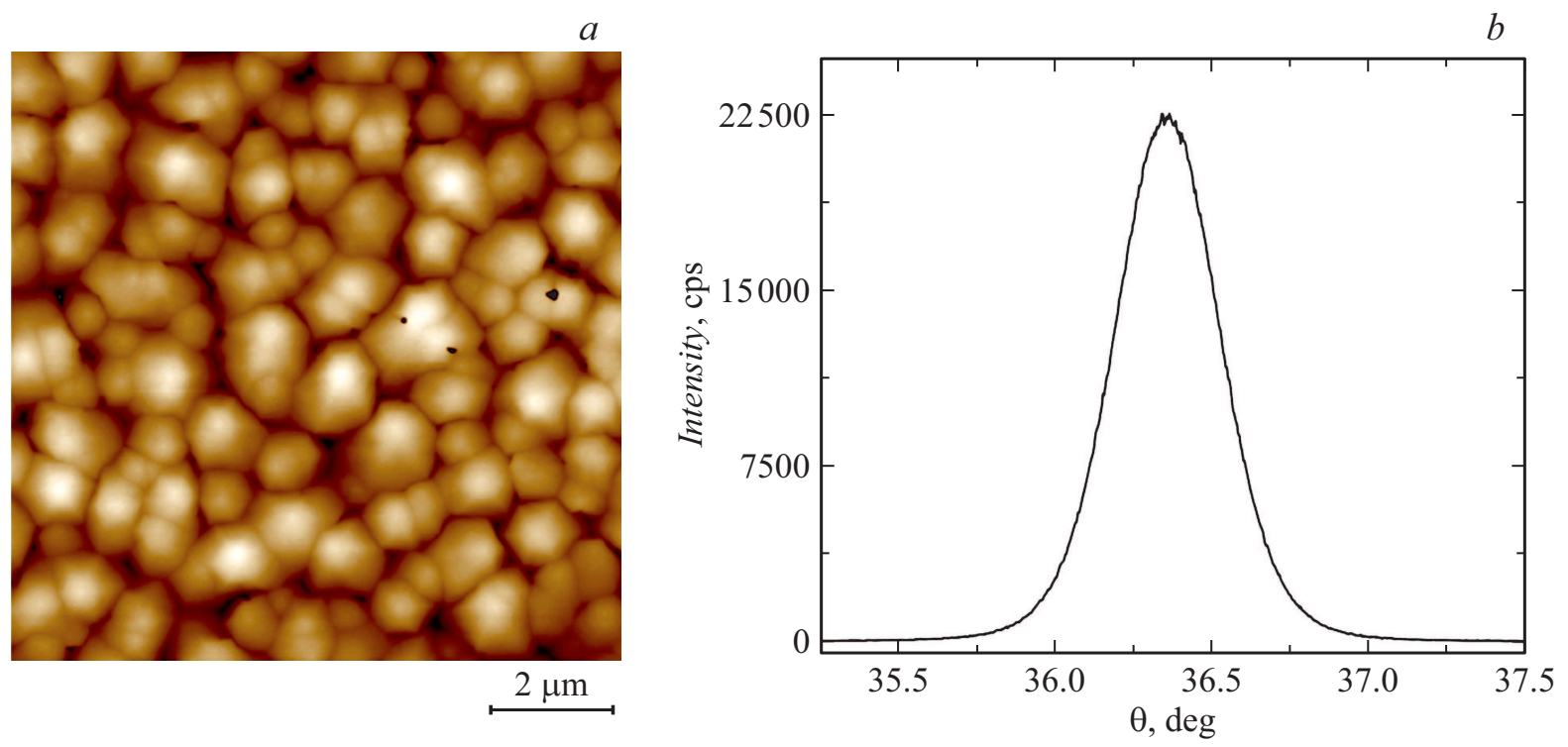

Рис. 3. $a-$ АСМ-изображение поверхности нитридной гетероструктуры на подложке кремния с алмазным теплоотводом $(10 \times 10 \mu \mathrm{m}) ; b-$ кривая качания дифракции рентгеновских лучей для рефлекса GaN 0002. 
изображенного участка равна $1.8 \mathrm{~nm}$. Данные рентгеновской дифракции были получены с использованием дифрактометра Rigaku SmartLab $\left(\mathrm{Cu} K_{\alpha}\right.$-излучение, длина волны $1.54 \AA$ ). Кривая качания дифракции рентгеновских лучей около отражения $\mathrm{GaN} 0002$ показана на рис. $3, b$. Ширина дифракционной кривой качания (FWHM) coставила $0.4^{\circ}$. Подвижность носителей в проводящем канале гетероструктуры и его слоевое сопротивление составляли $1600 \mathrm{~cm}^{2} /(\mathrm{V} \cdot \mathrm{s})$ и $300 \Omega / \square$ соответственно.

Итак, в работе были изготовлены подложки из поликристаллического алмаза с тонкой пленкой монокристаллического кремния размером $14 \times 14 \mathrm{~mm}$. Толщина кремния составила $234 \mathrm{~nm}$, слой алмаза имел толщину $250 \mu \mathrm{m}$ и теплопроводность $1290 \pm 190 \mathrm{~W} /(\mathrm{m} \cdot \mathrm{K})$, что в несколько раз выше теплопроводности карбида кремния. На данной подложке получена нитридная гетероструктура с двумерным электронным газом. Ширина дифракционной кривой качания для рефлекса $\mathrm{GaN} 0002$ составила $0.4^{\circ}$. Подвижность электронов в двумерном электронном газе и его слоевое сопротивление составили $1600 \mathrm{~cm}^{2} /(\mathrm{V} \cdot \mathrm{s})$ и $300 \Omega / \square$ соответственно. Таким образом, гетероструктуры на кремниево-алмазных подложках не уступают гетероструктурам на подложках кремния. Представленная технология формирования подложек кремния на алмазе является перспективной для электронных устройств с высоким удельным тепловыделением.

\section{Финансирование работы}

Работа выполнена при финансовой поддержке Национального исследовательского центра „Курчатовский институт".

\section{Конфликт интересов}

Авторы заявляют, что у них нет конфликта интересов.

\section{Список литературы}

[1] K. Husna Hamza, D. Nirmal, Int. J. Electron. Commun., 116, 153040 (2020). DOI: 10.1016/j.aeue.2019.153040

[2] F. Mu, R. He, T. Suga, Scripta Mater., 150, 148 (2018). DOI: $10.1016 /$ j.scriptamat.2018.03.016

[3] D. Meyer, T.I. Feygelson, T.J. Anderson, J.A. Roussos, M.J.Tadjer, B.P. Downey, D.S. Katzer, B.B. Pate, M.G. Ancona, A.D. Koehler, K.D. Hobart, C.R. Eddy, IEEE Electron Dev. Lett., 35 (10), 1013 (2014). DOI: 10.1109/LED.2014.2345631

[4] H. Tang, J.-M. Baribeau, G.C. Aers, J. Fraser, S. Rolfe, J.A. Bardwell, J. Cryst. Growth, 323 (1), 413 (2011). DOI: $10.1016 /$ j.jcrysgro.2010.11.063

[5] V.G. Ralchenko, A.A. Smolin, V.I. Konov, K.F. Sergeichev, I.A. Sychov, I.I. Vlasov, V.V. Migulin, S.V. Voronina, A.V. Khomich, Diamond Relat. Mater., 6 (2-4), 417 (1997). DOI: 10.1016/S0925-9635(96)00619-X

[6] A.A. Smolin, V.G. Ralchenko, S.M. Pimenov, T.V. Kononenko, Appl. Phys. Lett., 62 (26), 3449 (1993).

DOI: $10.1063 / 1.109045$
[7] A.V. Sukhadolau, E.V. Ivakin, V.G. Ralchenko, A.V. Khomich, A.V. Vlasov, A.F. Popovich, Diamond Relat. Mater., 14 (3), 589 (2005). DOI: 10.1016/j.diamond.2004.12.002

[8] I.O. Mayboroda, A.A. Knizhnik, Yu.V. Grishchenko, I.S. Ezubchenko, M.L. Zanaveskin, O.A. Kondratev, M.Yu. Presniakov, B.V. Potapkin, V.A. Ilyin, J. Appl. Phys., 122 (10), 105305 (2017). DOI: 10.1063/1.5002070

[9] L.L. Lev, I.O. Maiboroda, M.-A. Husanu, E.S. Grichuk, N.K. Chumakov, I.S. Ezubchenko, I.A. Chernykh, X. Wang, B. Tobler, T. Schmitt, M.L. Zanaveskin, V.G. Valeyev, V.N. Strocov, Nature Commun., 9 (1), 2653 (2018). DOI: $10.1038 / \mathrm{s} 41467-018-04354-\mathrm{x}$ 